\title{
Remote Sensing Approach for Environmental Monitoring: Application of Sudbury, Ontario, Canada
}

\author{
Rifaat Abdalla \\ Department of Hydrographic Surveying, Faculty of Maritime Studies \\ King Abdulaziz University, Jeddah, Saudi Arabia \\ E-mail: rmabdalla@kau.edu.sa \\ Abdulahad Malik \\ Department of Geomatics, University of Waterloo, Waterloo, Canada \\ Jonathan Sparlin \\ Department of Geomatics, University of Waterloo, Waterloo, Canada
}

Susanna Li

Department of Geomatics, University of Waterloo, Waterloo, Canada

Received: May 26, 2017 Accepted: July 16, 2017

doi:10.5296/emsd.v6i2.11610 URL: https://doi.org/10.5296/emsd.v6i2.11610

\begin{abstract}
ENVI and ArcGIS software along with Landsat TM data were used to evaluate sustainability and environmental conservation efforts in Sudbury region, Ontario, Canada. The study adopted three phase analysis. First, the change in landscape from 1984 to 2007 was studied. In the second part the study area was analyzed for urban heat island phenomenon by comparing thermal changes in relation to vegetation changes. The last part dealt with observing change in water quality parameter. Findings of the study revealed that significant change has taken place in Sudbury during the study period. Post classification comparison method has quantified the change and presented the results in the form of a change matrix, also an increase in the reclaimed land and dense vegetation in 2007 was observed while a significant decrease in the built up and barren land was also evident. Thermal analysis results
\end{abstract}


showed overall higher temperatures in 1984 while the thermal signatures of 2007 images showed characteristic of urban heat island where urban core of Sudbury had high temperatures while the rural and vegetative areas had low temperatures. The water quality analysis showed an increase in the levels of phosphorus and dissolved organic carbon (DOC) concentrations in lakes around Sudbury with the exception of Kelly Lake. The error analysis shown regression-derived phosphorus distribution maps were unreliable in this application, due to significant average error.

Keywords: Sustainability, Urban Change Detection, Landsat TM, Thermal Analysis, Water Quality, Error Analysis

\section{Introduction}

Many regions have developed and implemented environmental initiatives to improve the environmental conditions of their area. However, the daunting question is how many are successfully completely and how effective were the actions of the plan? In order to explore the answers for this question, the efforts of Vegetation Enhancement Technical Advisory Committee (VETAC) were studied for better understand the effects of Sudbury, Ontario's re-greening program performed by their VETAC committee. The sustainability and environmental enhancement for many regions can be achieved by different approaches (El-Kawy, Rød, Ismail, \& Suliman, 2011) (Rogan \& Chen, 2004) (Ortiz et al., 2008) Sustainability can be achieved by land reclamation, urban landscaping, and community outreach (Bin et al., 2006; Dewan \& Yamaguchi, 2009; Yeh \& Li, 1998). These plans were needed globally for land restoration in many parts of the world, because of fast progressing impact of the global climate change (Dahdouh-Guebas et al., 2002; Yeh \& Li, 1998)

The actions of community-based environmental restoration and sustainability might be very due to the varying public participation and the progressive development of international policies and regulations (Davies et al., 2008; Leach, Mearns, \& Scoones, 1999). The changes in green/vegetation and urban cover in urban centers, compare its land cover from over extended period of time based on trends and pattern identified from thermal temperature readings (Mansfield, Pattanayak, McDow, McDonald, \& Halpin, 2005). The heat island effect is a phenomenon that occurs in urban areas when there is more urban cover which means more solar radiation is being absorbed and re-emitted as heat resulting with higher thermal temperatures vs. more vegetation which means more solar energy is being used by many researchers including (Oke, 1982; Santamouris, Paraponiaris, \& Mihalakakou, 2007) to drive evapotranspiration resulting in lower temperatures. The relation of heat island effects of mining on lake water pollution was discussed by (Miller \& Armstrong, 1982; Trombulak \& Frissell, 2000), the impact is maximized in the urban centers due to the concentration of population. These results in patterns for distribution of thermal temperature readings over various hot spots and it relates to the effectiveness of initiatives in relation to the heat island effect.

(Schwarzenbach, Egli, Hofstetter, Von Gunten, \& Wehrli, 2010) and (Schwarzenbach, et al., 2010) have discussed the effect of mining water pollution and ways for environmental control and management for the purpose of improvements of the environmental quality. Landsat data 


\section{Macrothink}

analysis, the thermal band can be used to effectively model pollution (Black, Evans, Harshbarger, \& Zeigel, 1982; Maillard \& Santos, 2008) and to convert digital numbers to temperature readings and used to compare with land covers where patterns can be identified. Classification methods are used to process the Landsat images so that vegetation, urban, and other land covers can be easily identified and compared.

\section{Methodology}

\subsection{Pre-processing}

Data pre-processing for Landsat images was done before analyzing the images for vegetation, thermal, and water quality changes, in order to overcome these problems atmospheric and radiometric correction using PCI's ATCOR was applied

\subsection{Thermal Change}

In order to conduct thorough thermal analysis, the original data needs to be calibrated to temperature values that would have more meaning and can be understood easier compared to digital numbers. Figure 1 below shows the processes for thermal analysis.

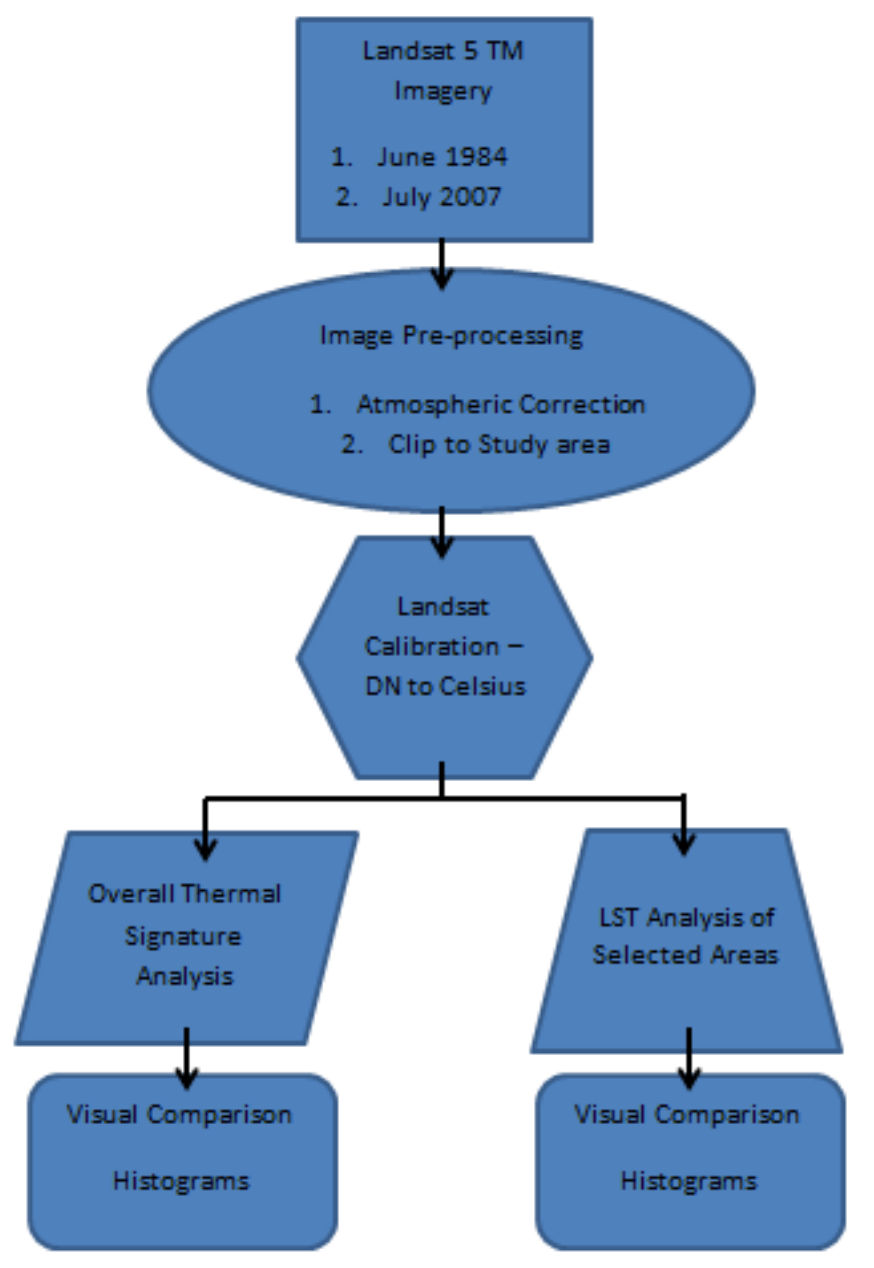

Figure 1. Progression of thermal change methodology 


\section{Ml Macrothink}

There are two ways of doing this, depending on the information that is available with the data using the Gain and Bias (or offset) values from the header file (Equation 1), or using the LMIN and LMAX spectral radiance scaling factors (Equation 2). Values were located in the metadata and on the USGS website. Both formulas were used to compare which produced better results. The outcomes generated from both formulas were pretty similar, therefore only one of the outcomes were used for analysis.

The formula for using the Gain and Bias values is:

$$
\mathrm{CV}_{\mathrm{R} 1}=\text { gain } * \mathrm{DN}+\text { bias }
$$

Where:

CVR1 is the cell value as radiance

$\mathrm{DN}$ is the cell value digital number (thermal band)

gain is the gain value for a specific band

bias is the bias value for a specific band

The formula for using LMIN and LMAX

$$
\mathrm{CV}_{\mathrm{R} 1}=\left(\left(\mathrm{LMAX}_{\lambda}-\mathrm{LMIN}_{\lambda}\right) /(\mathrm{QCALMAX}-\mathrm{QCALMIN})\right) *(\mathrm{QCAL}-\mathrm{QCALMIN})+\mathrm{LMIN}_{\lambda}
$$

Where:

$\mathrm{CV}_{\mathrm{R} 1}$ is the cell value as radiance $\mathrm{QCAL}=$ digital number

$\operatorname{LMIN}_{\lambda}=$ spectral radiance scales to QCALMIN

$\mathrm{LMAX}_{\lambda}=$ spectral radiance scales to QCALMAX

QCALMIN = the minimum quantized calibrated pixel value (typically $=1)$

QCALMAX $=$ the maximum quantized calibrated pixel value $($ typically $=255)$

After the values have been converted to radiance, the Planck's function was then applied to the values to convert them to Kelvin (Equation 3):

$$
\mathrm{T}=1260.56 / \operatorname{alog}(((607.76 * 0.95) / \mathrm{B} 1)+1)
$$

Where:

$\mathrm{T}$ is degrees Kelvin

$\mathrm{B} 1$ is the radiance values from the previous output

After the pixel values were in Kelvin, there is one more step to in converting the values to Celsius. All the values were converted to Celsius by subtracting 273.15 using band math.

\subsection{Land-cover Change}

Two TM data from Landsat 5, one acquired from May 1984 and other from July 2007 were used in this research for the investigation of land cover change caused by the vegetation 
reclamation efforts by the Region of Sudbury, as shown in Table 1. Although it was difficult to acquire the images for the anniversary dates, however, the images were from the same season in order to minimize the impacts of seasonal differences of vegetation. In addition, all Landsat 5 images used in this research were downloaded from USGS website and belonged to USGS.

Table 1. Metadata summary for Thermal \& Land-cover Landsat data

\begin{tabular}{|l|l|l|}
\hline Metadata & Earlier Image & Later Image \\
\hline Platform & Landsat 5 & Landsat 5 \\
\hline Sensor & TM & TM \\
\hline Acquisition Date & June 4th, 1984 & July 22nd, 2007 \\
\hline Scan Time & $15: 37: 17.7$ & $15: 50: 30.5$ \\
\hline Scan Time Temp. & 27.1 to $26.7^{\circ} \mathrm{C}$ & 25.3 to $24.8^{\circ} \mathrm{C}$ \\
\hline Path & 19 & 19 \\
\hline Row & 28 & 28 \\
\hline Scene UL Lat. & 46.9974867 & 46.9924596 \\
\hline Scene UL Long. & -82.2140144 & -82.1783906 \\
\hline Spatial Resolution & 30 metres & 30 metres \\
\hline
\end{tabular}

Figure 2 below illustrates the detailed analysis of Sudbury's land change detection methods used in this study. All the analyses were carried out using ENVI and ArcGIS. Three change detection techniques including image differencing, principal component analysis, and post classification comparison were used in this research to determine the changes that have occurred in Sudbury during the period of 1984 to 2007.

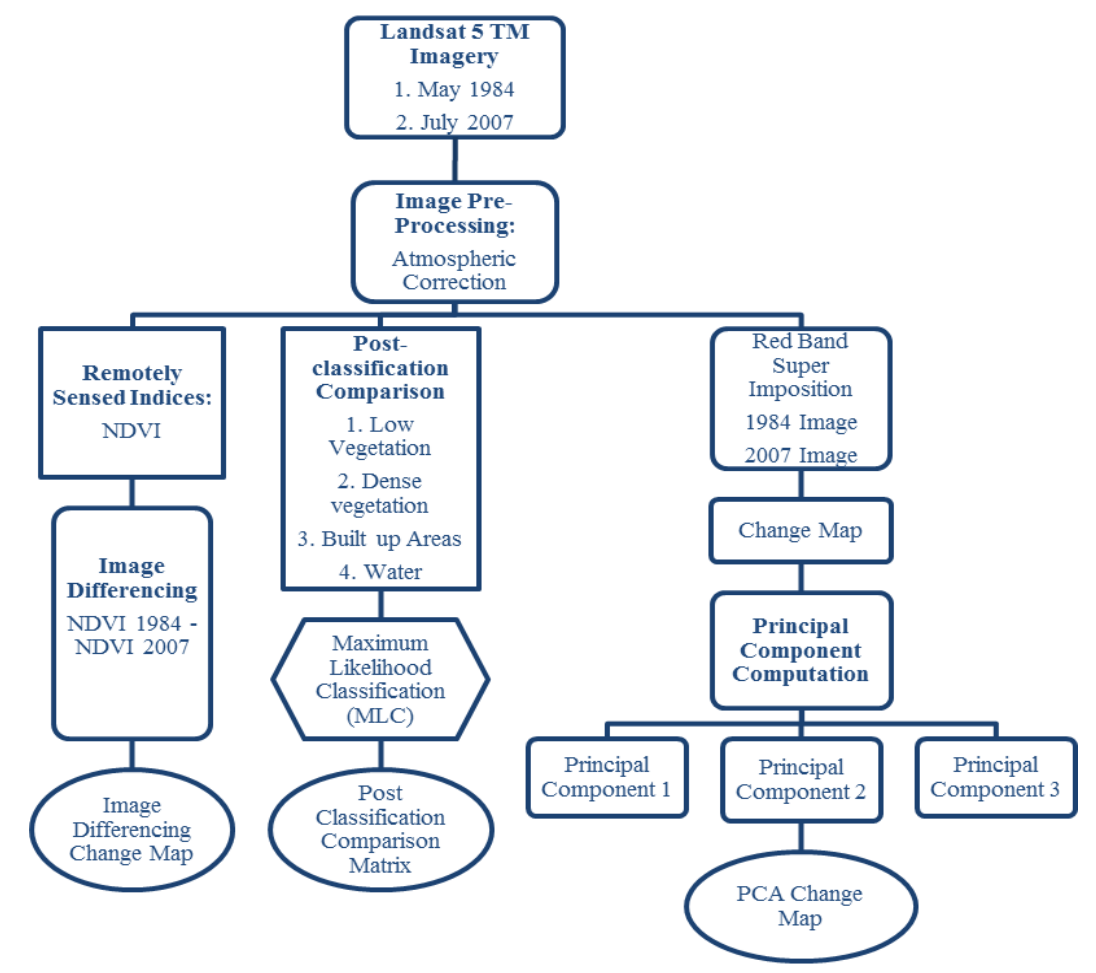

Figure 2. Progression of land-cover change methodology 
In this method the two images from different time periods are subtracted from each other to produce an image that represents the change between the two. The subtraction results in positive and negative values in areas of radiance values and zero values in areas of no change (Jenson, 2005). This method is represented by Equation 4 below:

$$
\Delta \mathrm{BV}_{\mathrm{ijk}}=\mathrm{BV}_{\mathrm{ijk}}(1)-\mathrm{BV}_{\mathrm{ijk}}(2)+\mathrm{c}
$$

In Equation 4, $\mathrm{BV}_{\mathrm{ijk}}$ refers to the total change in the pixels after brightness value on date 2, $\left(\mathrm{BV}_{\mathrm{ijk}}(2)\right.$ is subtracted from brightness value on date $1\left(\mathrm{BV}_{\mathrm{ijk}}(1)\right)$, and $\mathrm{i}, \mathrm{j}$, and $\mathrm{k}$ represent line \#, column \# and TM band respectively.

NDVI images from 1984 and 2007 were integrated in the image differencing approach for discriminating between vegetative and non-vegetative areas. Image differencing functionality in ENVI was used to derive the differencing map shown in the results. The differencing map was highly dependent on the threshold value chosen for defining classes. Seven classes were chosen, some of which were then merged together. Therefore, the final differencing map represented four major classes.

Principal component analysis was the second change detection method used to study land cover change in Sudbury (Mahmoodzadeh, 2007). The two classified images are then compared on pixel by pixel basis and produces change detection matrix. The images were classified using Maximum Likelihood algorithm based on supervised classification. The change detection statistics tool in ENVI was used to generate post classification comparison matrix.

\subsection{Lake Water Quality}

The methodology for the water quality assessment of Sudbury's surrounding lakes consisted of four phases: data acquisition and initial processing, preparing the data for regression, performing simple linear regression, and mapping the water quality parameter.

\subsubsection{Data Acquisition \& Initial Processing}

In order to map the distribution of water pollutants using remote sensing ground truthing data was needed to calibrate the instrument. After much searching Greater Sudbury's municipal website was found to list some historical water quality data and therefore was relied upon for this portion of the project. This published water quality data was most frequent and complete in 1990 and 2004 and thus became the study's focussed time period. Once this ground truthing data was acquired the complimenting Landsat TM data (1990 and 2004 cloud-free anniversary date images in late spring) was obtained from the USGS GLOVIS collection.

\subsubsection{Prepare Data for Regression}

Once all the required data was acquired and pre-processed the second phase - preparing the data for regression - commenced. The purpose of this phase was the combine the water quality data and the satellite reflectance data together so that linear regression could be performed. First ESRI's ArcMap was used to create two point geospatial layers (one for 1990 and the other for 2004) representing where all the in-situ water samples (of Sudbury's lakes) 
were taken: since no specific coordinates accompanied the water quality data (another major limitation; explained further in the conclusion) points were chosen in the middle of their respective lakes (an aim to comply with Sudbury's sampling methodology; "usually the deepest part of the lake," - Greater Sudbury, 2011). The water quality data was then added to these geospatial layers' attribute-tables (e.g. 1990 water quality data added to 1990 attribute-table). The final step in this phase was to utilize ArcMap's Extract Multi-Values to Points tool: reflectance values from each individual Landsat band (except TM6) were extracted to its respective geospatial layers' attribute table (e.g. 1990 Landsat TM bands 1-5 $\& 7$ to the 1990 attribute-table).

\subsubsection{Simple Linear Regression}

The goal of this third phase was to explore predictive relationships between individual Landsat bands and water quality measurements taken in the field (e.g. would TM4 be able to accurately predict the $\mathrm{pH}$ of lake water?). With all the necessary data assembled together the geospatial layers' attribute-tables (i.e. the shapefile's .dbf file) were accessed and manipulated in Excel. R-square values were calculated between each water quality parameter (albeit ones that were consistently measured in both 1990 and 2004) and each TM band (using Excel's '=RSQ(list_y, list_x)' function). Once calculated R-square values were compared between the 1990 and 2004 data in order to identify a TM band that consistently achieved a high relative R-square value with a given water quality parameter and therefore could potentially have an explanatory relationship (water quality parameter being the independent variable and TM band being the dependent variable).

\subsubsection{Map Water Quality Parameter}

Since the linear trend-line between a TM band and a WQP modelled an approximate relationship between the two variables (i.e. only strong and consistent relationships passed along from phase 3) it could be utilized to map the WQP of interest. To do this the trend-line's slope and intercept of strong and consistent TM-WQP relationships were first

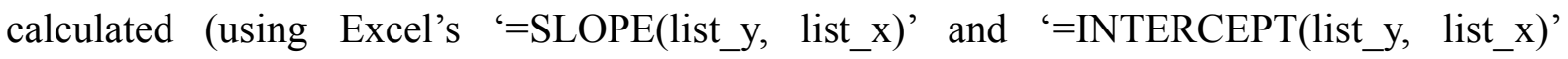
functions). Next ArcMap's Modelbuilder batch processing tool was used to apply Equation 5 to the entire TM band:

$$
Q=\frac{P-I}{S}
$$

where $Q=$ Predicted $W Q P$ value

where $P=T M$ Band Pixel value

where I $=$ Trend - Line Intercept

where $S=$ Trend - Line Slope 


\section{Ml Macrothink}

The output of the applied equation was an image depicting the spatial distribution of the WQP's concentration across the study area. To make the 1990 and 2004 images comparable both images were reclassified (by altering the image's symbology - not permanent) so that consistent bin-thresholds categorized the pixels. Finally, to determine where the WQP concentrations were experiencing change the 1990 output image was subtracted from the 2004 output image with the resulting image also being reclassified for easier analysis.

\subsubsection{Accuracy Assessment}

Once the WQP maps were generated an accuracy assessment was performed to measure the model's level of success and consequently the level of confidence in the WQP maps. To do this the values of the generated WQP map were extracted to the geospatial point layer's attribute-table using ArcMap's Extract Value to Point tool (similar to the tool used in phase 2).

\section{Results}

\subsection{Thermal Change}

Once the original images have been calibrated to Celsius temperature values, certain outputs are compared. Figure3 shows the two output images generated from the calibration processes. Dark purple values show high temperature values and yellow represents low values. Evidently, the 1984 image displays values of closer range as represented by a majority of red pixels, whereas the 2007 image displays a wider range of values where the centre urban area is more defined and values decrease as pixels are further from the centre. The 2007 images shows a larger difference between its centre values compared to the countryside values.
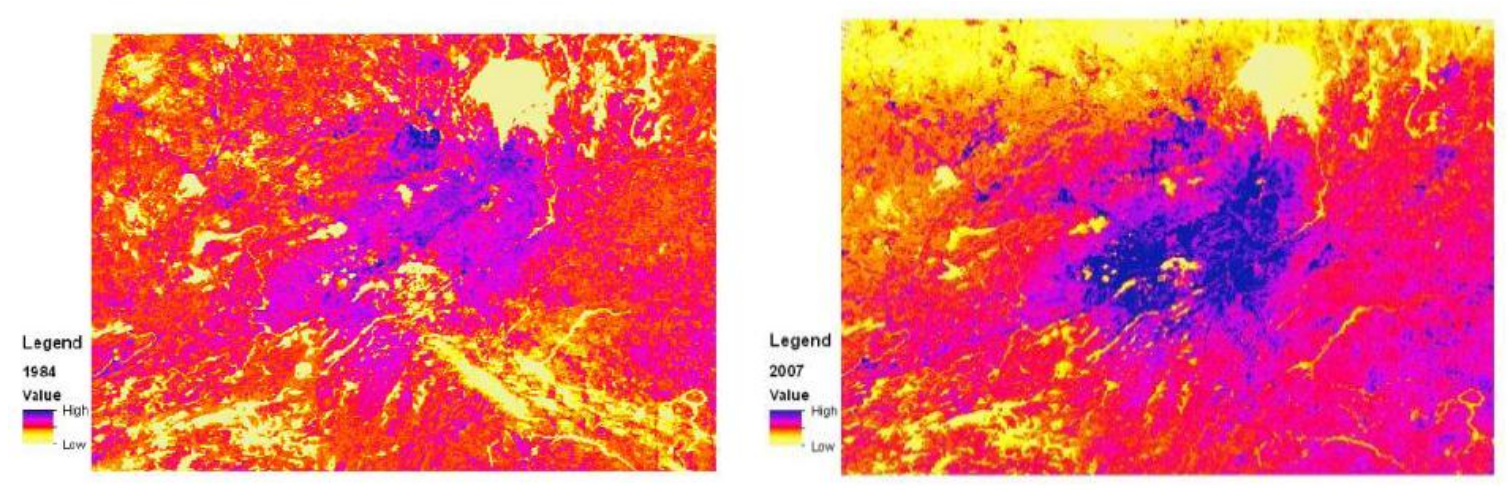

Figure 3. Comparison of overall thermal signatures

Figure 4 below shows the two histograms generated from the two images in Figure 3. These histograms show a more quantitative comparison of the two output images. The y-axis values for the 2007 histogram are slightly higher in order to incorporate the entire histogram within the window. This shows that the 2007 image has more pixel values around the average value whereas the 1984 image have values that distribute more evenly. But on the other hand, the mean for the 1984 image is slightly higher at 19.48 compared to the 2007 mean of 17.15 , therefore it means that even though the range in values for the 1984 image is smaller, its 


\section{Macrothink}

Environmental Management and Sustainable Development

ISSN 2164-7682 2017, Vol. 6, No. 2

mean is still higher than the 2007 image. The 2007 image produces a histogram that is taller vertically, but also wide on the base due to the larger range of values.

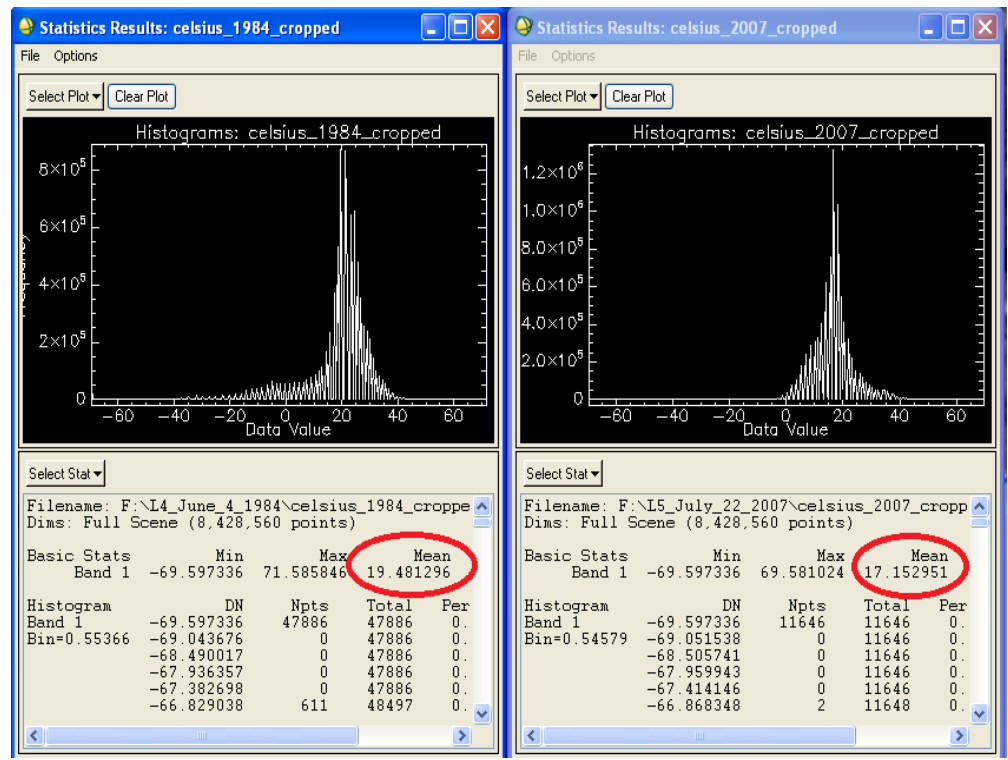

Figure 4. Histograms of output thermal images

Figure 5 below displays histograms generated from the same selected areas within each image to compare certain LSTs. Histograms on the top compare vegetated areas and the ones on the bottom compare urban or barren land areas, histograms on the right are from 1984 image and on the left are from 2007 image. The 1984 histograms have values that are more evenly distributed or have more of a trend where the plot increases to the data values with the highest number of pixels then decreases, forming triangular plots.

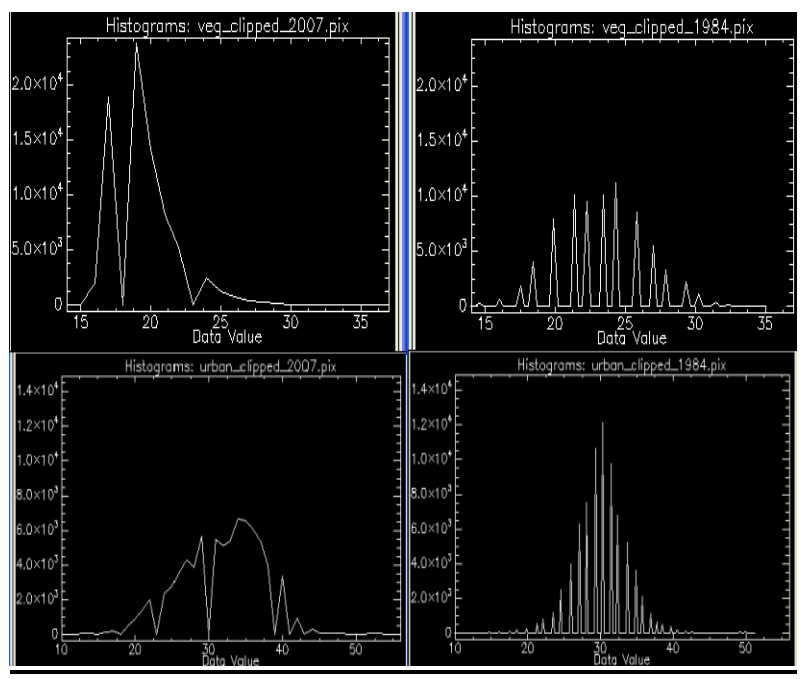

Figure 5. Histograms for selected area comparisons

Figure 6 shows the selected vegetated areas displayed with colour representation of the temperature values. Brighter colours represent higher values and darker colours represent lower values. As shown in the image below, the vegetated area in the 1984 image has higher 


\section{Macrothink}

Environmental Management and Sustainable Development

ISSN 2164-7682 2017, Vol. 6, No. 2

values compared to the 2007 image. Certain areas in the 1984 image show extremely different temperature values, in the circled area in the 1984 image many pixels are represented in red show high temperatures at those land covers. The 2007 image has much less areas represented in white or red. The circled area shows very different temperature values as there are high temperature in the 2007 image and low temperature in the 1984 image, this can be caused if there was a change in land cover.
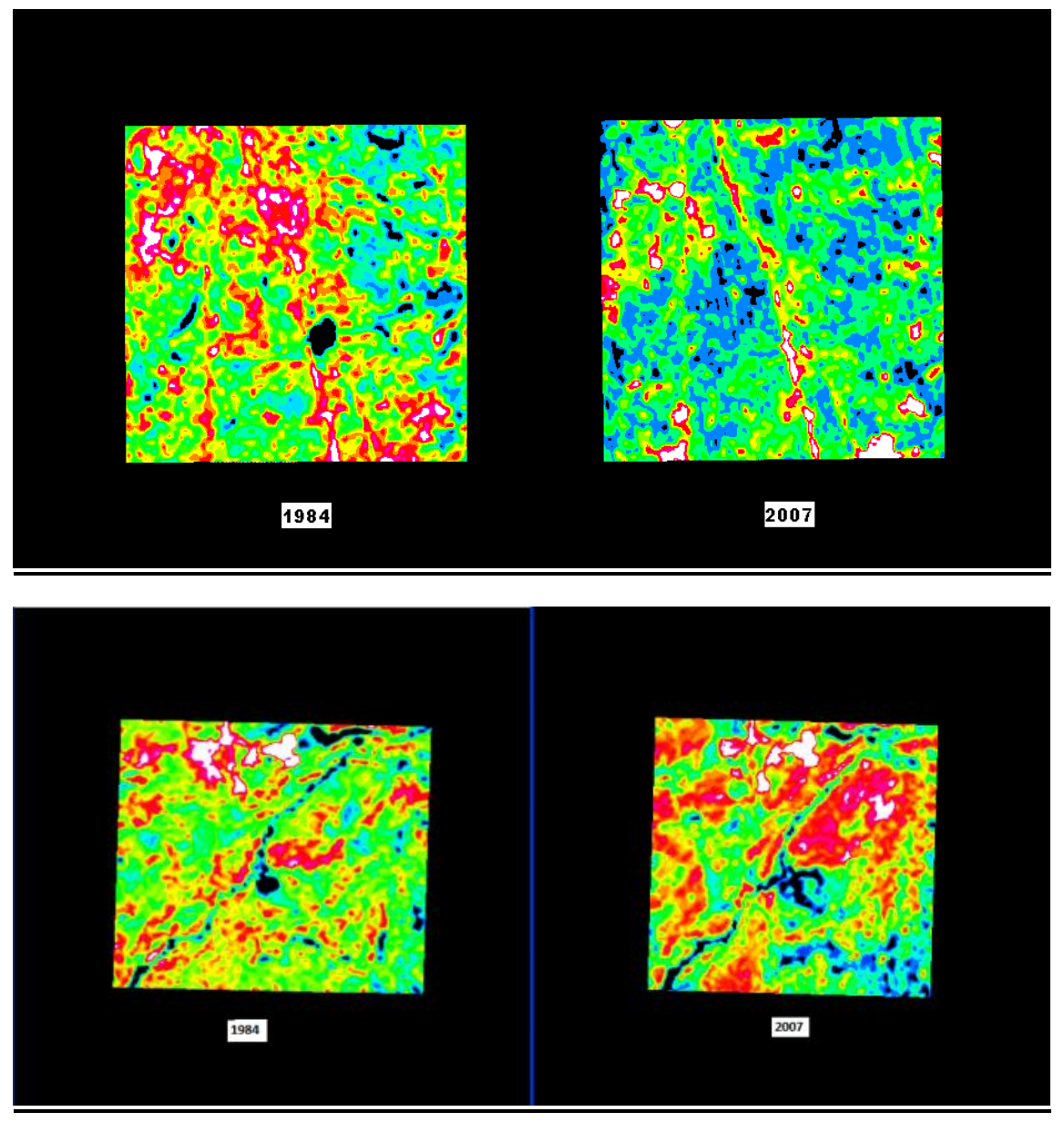

Figure 6. Comparisons between coloured images of selected vegetation and urban/barren land areas

\subsection{Land-cover Change}

During the image differencing process NDVI was first implemented for 1984 and 2007 images. Subsequently, the results generated from NDVI transformation were then used as input for the image differencing function. Figure 7 below represents the two NDVI images from 1984 and 2007. In this study NDVI values were categorized into six classes for evaluation mechanism of green space in Sudbury. It is clear from the results that dense vegetation (i.e. $0.5<$ ) has significantly increased from 1984 to 2007. 


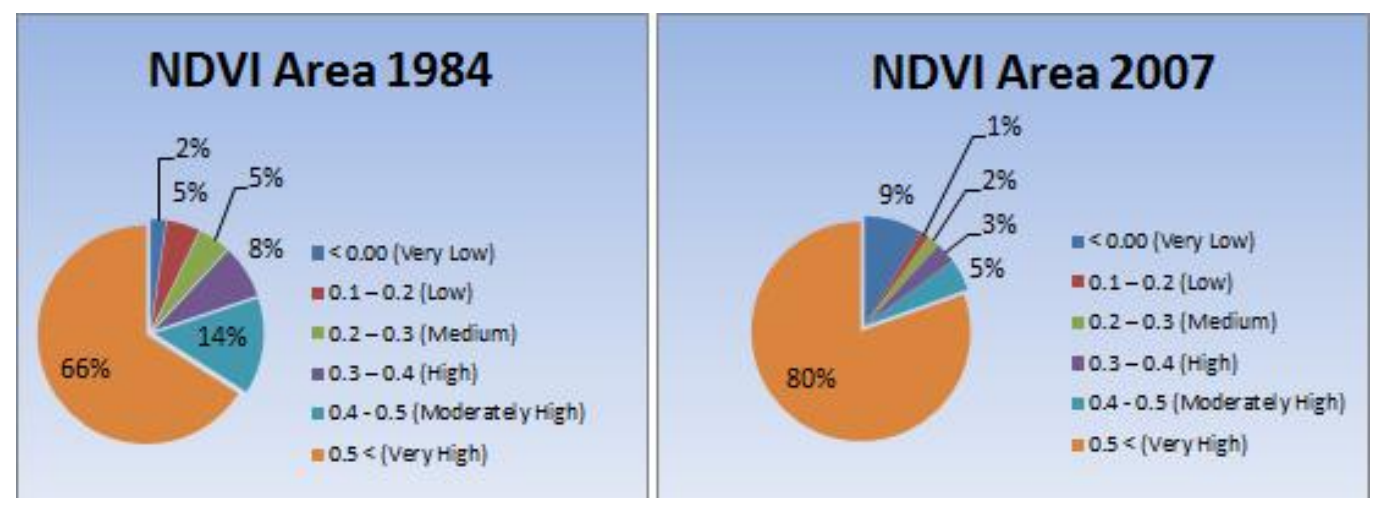

Figure7. NDVI density changes - 1984 to 2007

Additionally, Figure 8 below highlights the changes in area of classes between the two years: it is clear that dense vegetation represented 66\% of the total study area in 1984 while in 2007 it significantly increased to $80 \%$ of the total study area.

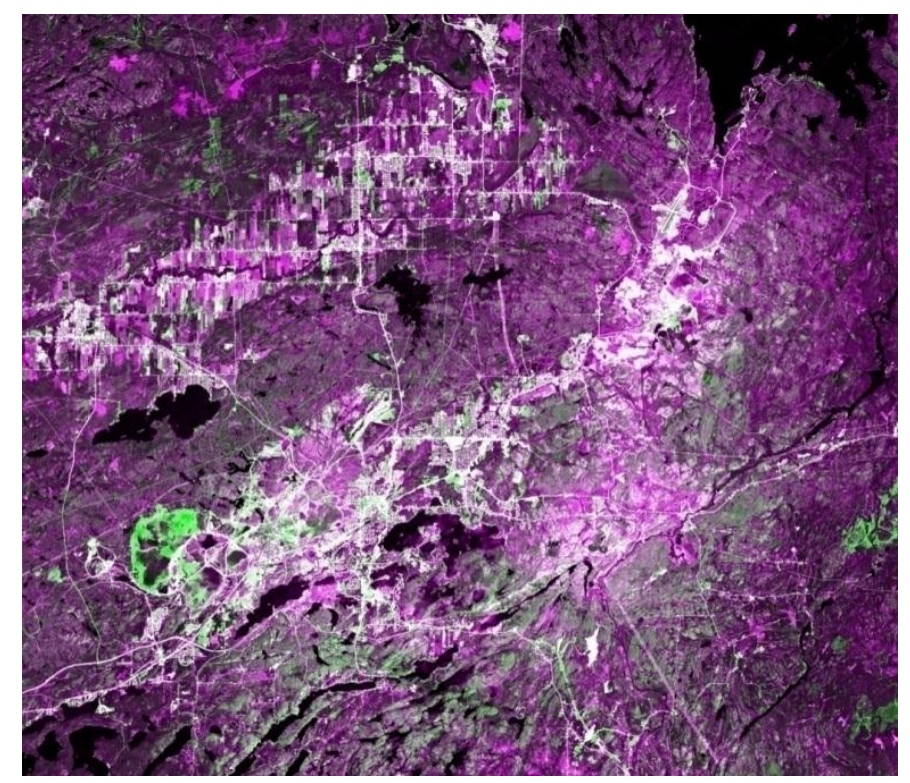

Figure 8. Change categories highlighted in the image differencing output

Next, the NDVI images were used to derive image differencing output shown in below in Figures 9 \& 10. The image differencing output represents 4 classes which include no change, significant change, sparse to dense vegetation, and loss of vegetation. The no change category represents the areas that were same in both 1984 and 2007 images. The significant change category represents the areas that were either barren land or built up areas in 1984 and were modified or converted into vegetative land. Sparse to dense vegetation represents the areas that had thin vegetation in 1984 and overtime became thick and dense vegetative areas. Lastly, loss of vegetation category represents areas that were vegetative land in 1984 but were converted to built-up areas.

Principal component analysis was the second method used to analyze change in the following study. For this method a change map by combining the red bands from 1984 and 2007 image 


\section{Macrothink}

were used to create the map shown in Figure 9.

The determining factor for choosing the number of components for analysis relies on the shape of the curve. If the curve shows an elbow, which in this case is between 2 and 3 , this is often indicates that higher order principal components contribute a decreasing amount of additional variance and so might not be needed., only the first two components were selected to be analyzed as shown in Figure 10.

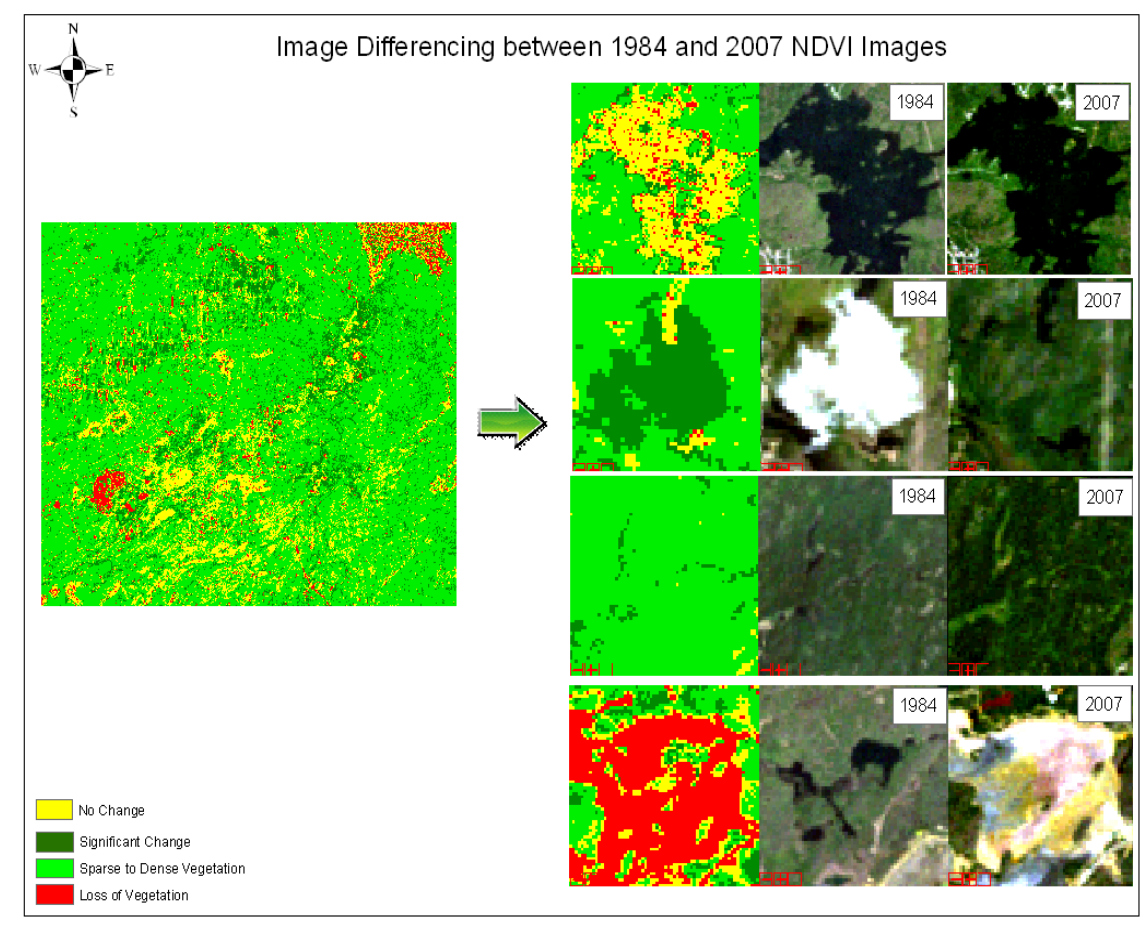

Figure 9. Change detection by stacking 1984 and 2007 TM3 bands

Principal component 1 did not represent any change but depicted areas which were same in both 1984 and 2007 images using white and black colors. However, principal component 2 effectively depicted change between 1984 and 2007 by representing the re-growth areas in white and loss of vegetation in black colour.

Next, principal component 2 was used to generate a from-to map (Figures 10) using density slice. Figure 11 represents the overall change map derived from using principal component 2 and density slice while Figure 12 shows the type of change depicted by each class. 


\section{Macrothink}

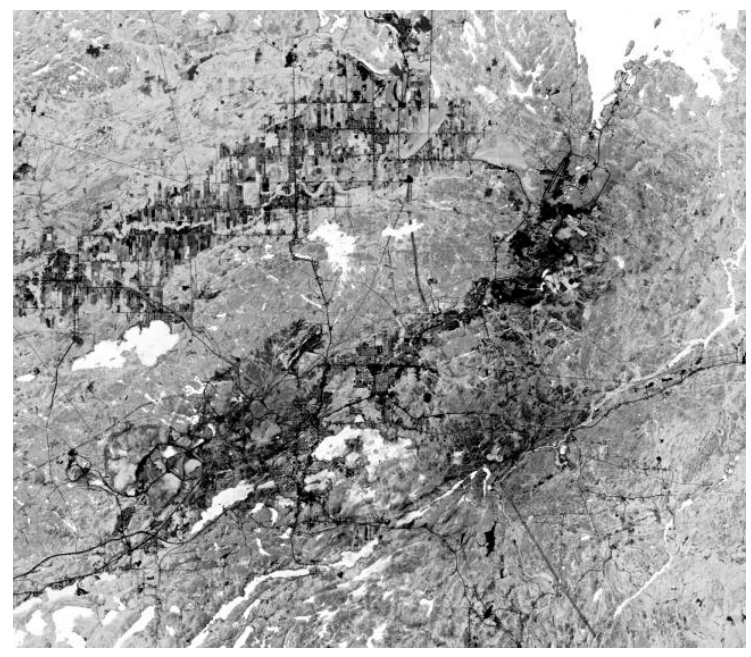

Principal Component 1

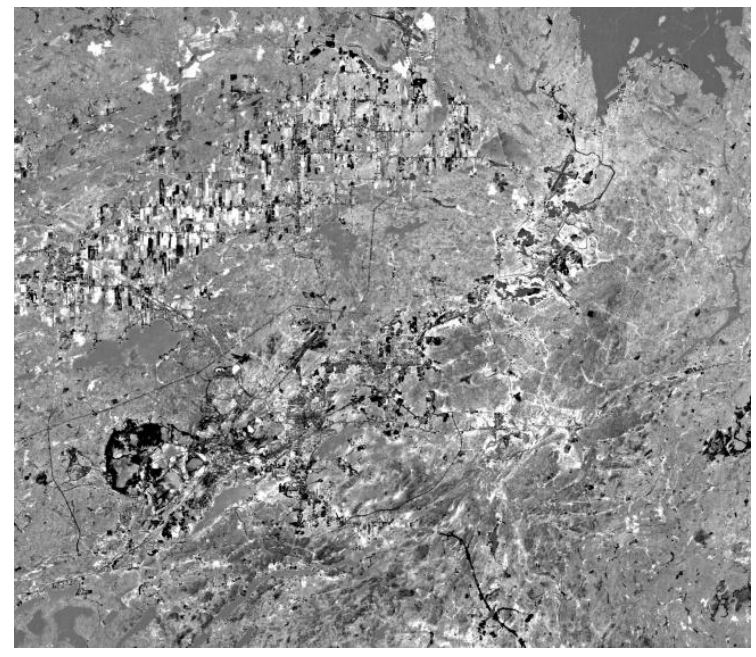

Principal Component 2

Figure 10. Change detection principal components 1 and 2

Post classification was the last method used to analyze land cover change in Sudbury. Supervised land cover classification of each Landsat image was implemented by using Maximum Likelihood Classification, in which four classes were selected including Low vegetation (reclaimed land), dense vegetation, built-up/barren land, and water as shown in Figures 11 and 12 below.

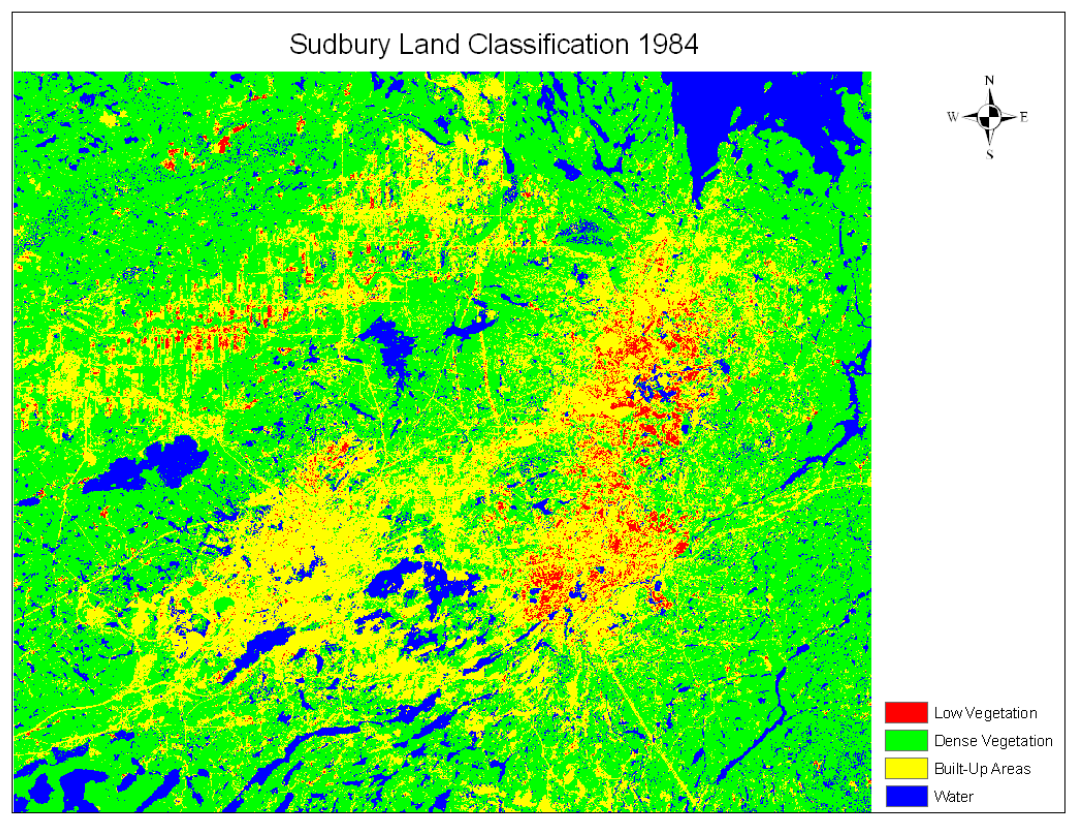

Figure11. Land-cover classification of 1984 image 


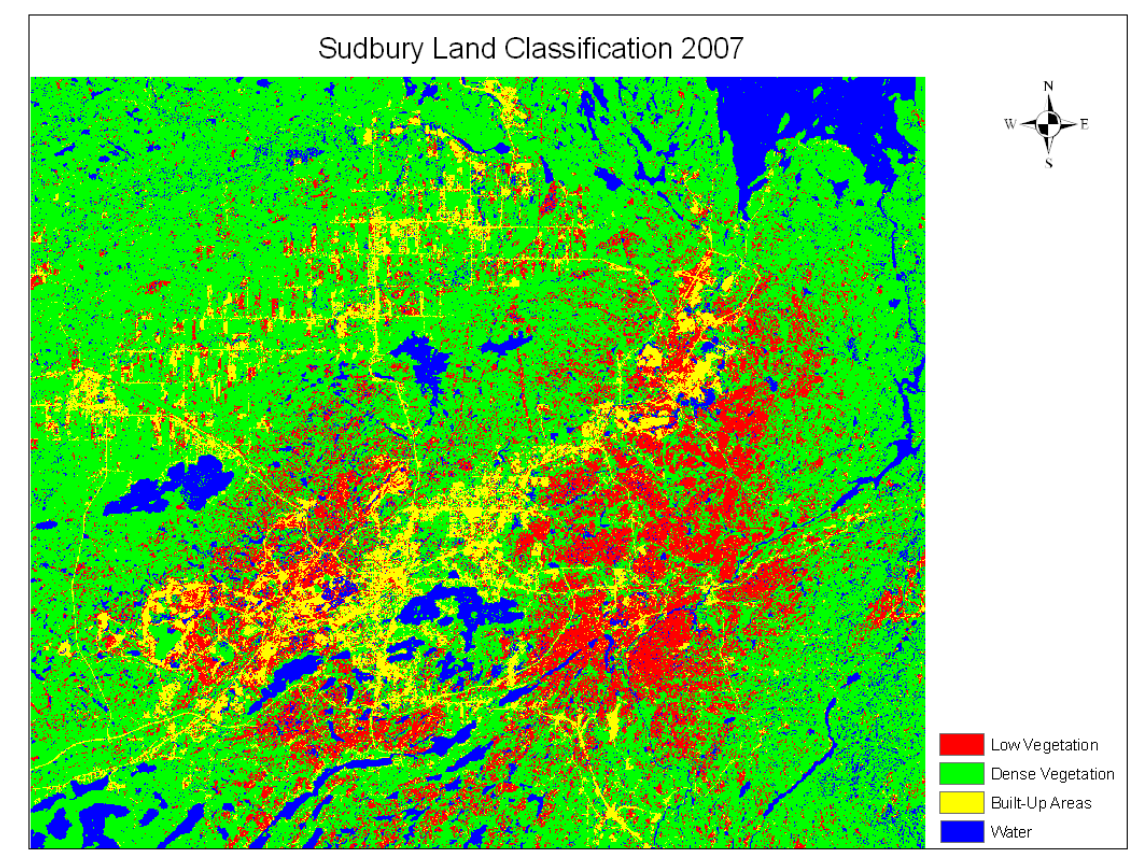

Figure 12. Land-cover classification of 2007 image

By observing the two images it is clear that in 1984 a large portion of the study area was covered with built-up and barren land while there were few spots representing reclaimed or low vegetation areas. However, in 2007 the topography of the study area has significantly changed. It is evident that reclaimed areas have considerably increased in 2007 and built-up and barren land has been greatly reduced.

The major highlight of the post classification method was that it generated quantitative results. Table 2 below represents the post classification comparison matrix that was generated using the classified images above.

Table 2. Post classification change matrix

\begin{tabular}{|l|l|l|l|l|l|}
\hline & $\begin{array}{l}\text { Reclaimed } \\
\text { Land }\left(\mathbf{m}^{\mathbf{2}}\right)\end{array}$ & $\begin{array}{l}\text { Water } \\
\left(\mathbf{m}^{\mathbf{2}}\right)\end{array}$ & $\begin{array}{l}\text { Dense Vegetation } \\
\left(\mathbf{m}^{\mathbf{2}}\right)\end{array}$ & $\begin{array}{l}\text { Urban/Barren } \\
\text { Land }\left(\mathbf{m}^{\mathbf{2}}\right)\end{array}$ & $\begin{array}{l}\mathbf{2 0 0 7} \text { Class } \\
\text { Total }\left(\mathbf{m}^{\mathbf{2}}\right)\end{array}$ \\
\hline Reclaimed Land $\left.\mathbf{( m}^{\mathbf{2}}\right)$ & $20,797,200$ & $18,480,600$ & $119,372,400$ & $150,031,800$ & $308,682,000$ \\
\hline Water $\left(\mathbf{m}^{\mathbf{2}}\right)$ & $1,431,900$ & $128,499,300$ & $47,700,900$ & $23,685,300$ & $201,317,400$ \\
\hline Dense Vegetation $\left(\mathbf{m}^{\mathbf{2}}\right)$ & $11,360,700$ & $45,152,100$ & $847,271,700$ & $201,486,600$ & $1,105,271,100$ \\
\hline Urban/Barren Land $\left.\mathbf{( m}^{\mathbf{2}}\right)$ & $4,982,400$ & $3,358,800$ & $30,579,300$ & $115,140,600$ & $154,061,100$ \\
\hline $\mathbf{1 9 8 4}$ Class Total $\left.\mathbf{( m}^{\mathbf{2}}\right)$ & $38,572,200$ & $195,490,800$ & $1,044,924,300$ & $490,344,300$ & - \\
\hline Class Changes & $17,775,000$ & $66,991,500$ & $197,652,600$ & $375,203,700$ & - \\
\hline $\mathbf{2 0 0 7} \mathbf{- 1 9 8 4}$ & $270,109,800$ & $5,826,600$ & $60,346,800$ & $-336,283,200$ & - \\
\hline
\end{tabular}

In the table above the 1984 class total row indicates the area $\left(\mathrm{m}^{2}\right)$ in each initial state class and the 2007 class column indicates the area $\left(\mathrm{m}^{2}\right)$ in each final state class. The row total column is simply a class-by-class summation of all final state pixels that fell into the selected initial state classes (ENVI help, 2011). The class changes row indicates the total number of Initial 


\section{Mll Macrothink}

Environmental Management and Sustainable Development

ISSN 2164-7682

2017, Vol. 6, No. 2

State area that has changed classes. Finally, 2007-1984 is simply the difference in the total number of equivalently classed area in two images, computed by subtracting the initial state class totals from the final state class totals. The positive values of 2007-1984 indicate that the class size has been increased while a negative value indicates a decrease in the class size.

Based on the above explanation, it is evident that the area of reclaimed land has been increased since 1984 along with the area of water and dense vegetation. The built-up and barren land has significantly decreased which justifies our initial claim about Sudbury's landscape reclamation program.

\subsection{Lake Water Quality}

\subsubsection{Regression Results}

Of all the water quality parameters Sudbury measured and provided on their municipal website only five were consistently measured in both 1990 and 2004 (dissolved organic carbon - DOC, sulphate, conductivity, alkalinity, and phosphorus): only these five WQPs were subjected to the methodology. Only when linear regression was complete was it realized that all TM-WQP relationships (i.e. R-square values) were unsatisfactory statistically to perform a predictive model (R-square values range from 0.0 to 1.0 - the higher the value the better the independent variable explains the dependent variable). A summary of the linear regression process performed on all five WQPs are presented in Table 3 below.

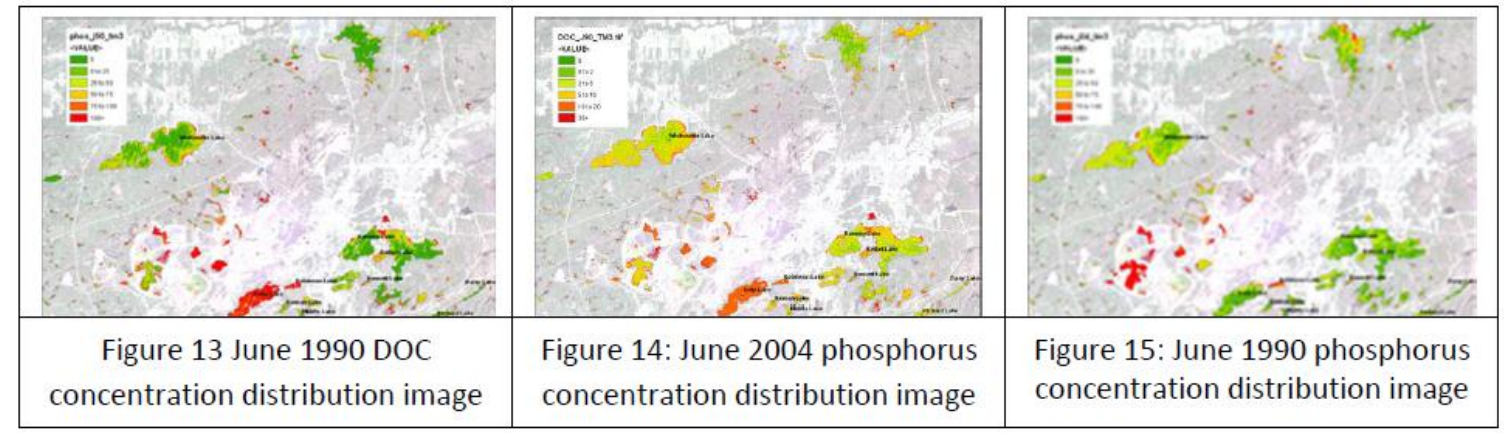

Cells highlighted in yellow were the TM bands chosen to be considered for the predictive model of its respective WQP relationship. For example, TM3 was chosen selected for DOC because it consistently had a high (relative to other TM bands) R-square value $\left(1990 \_\right.$TM3/DOC R-square $=0.62$ ranked $2^{\text {nd }}$, and 2004_TM3/DOC R-square $=0.15$ ranked $1^{\text {st}}$; compare with 1990_TM5/DOC R-square $=0.64$ ranked $1^{\text {st }}$, and 2004_TM3/DOC R-square $=0.01$ ranked $5^{\text {th }}$ ).

To ensure that the TM-WQP relationships were not random the 1990 and 2004 trend-lines of these relationships were compared with only TM-WQP relationships being accepted for WQP spatial distribution mapping if their slopes appeard to be similar. As shown in Figure 13 only phosphorus and dissolved organic carbon met this criteria and were passed on to the next phase.

Figures 14 and 15 show the resulting 1990 and 2004 phosphorus distribution maps derived from their respective phosphorus-TM3 models. In these distribution images red indicates 


\section{Ml Macrothink}

areas of high phosphorus concentration (thresholds are subjective and consistent, chosen for easy comparison between the earlier and later images) and green indicates areas of low phosphorus concentration.

Figure 16 shows the change in phoshorus concentrations from 1990 to 2004: red indicates a substantial increase in phosphorus concentration while green indicates a substantial decrease in phosphorus concentration. Similarly, Figures 17 and 18 show the resulting 1990 and 2004 DOC distribution maps derived from their respective DOC-TM3 models. Red indicates high DOC concentrations while green indicates low DOC concentrations. Figure 27 shows the change in DOC concentrations from 1990 to 2004: red indicates a substantial increase in DOC while green indicates a substantial decrease in DOC.

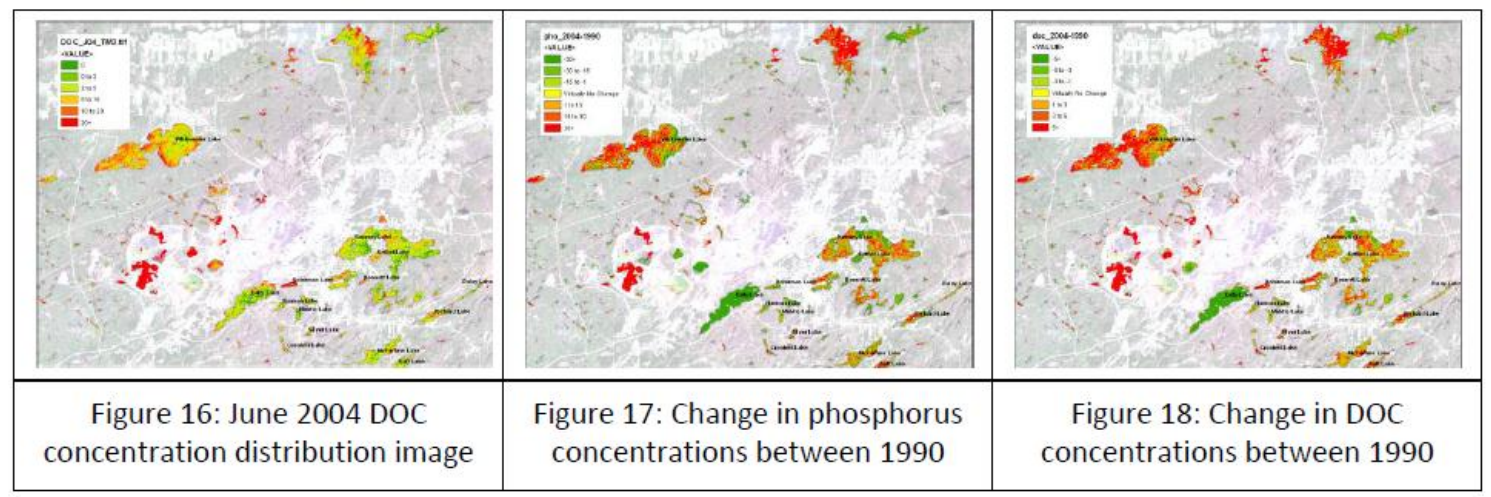

The error analysis performed on the DOC regression models reported mediocre errors for both the 1990 and 2004 distribution images and significantly worse errors for both the 1990 and 2004 distribution images from the phosphorus regression models. Figure 20 below summarizes the regression model error analysis: the regression model image with the best accuracy was the 1990 DOC image with an average error of 1.72 while the most inaccurate regression model image produced was the 1990 phosphorus image with an average error of 42.11. The higher the error the less confidence can be placed in the image.

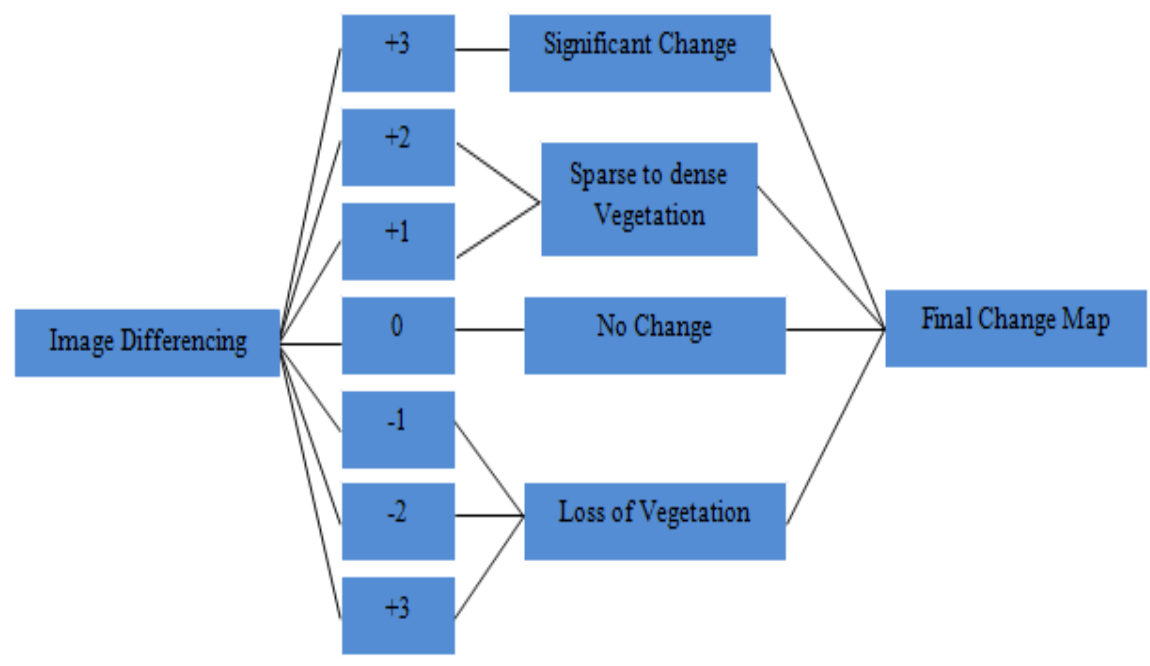

Figure 20. Process used to derive final image differencing change map 


\section{Macrothink}

\section{Discussion}

\subsection{Thermal Change}

Through much analysis, it is definitely evident that different land covers have different thermal properties and greatly affect the thermal characteristics of the Greater Sudbury region. VETAC's initiatives have changed much of the landscape of Sudbury, allowing their environment to increase in vegetated areas, decrease in barren lands, as well as decrease in pollution (lake water, soil, and air).

\subsubsection{Overall Thermal Signature}

Comparison of the overall thermal signatures of the two output images visually and quantitatively shows a general decrease in overall temperatures in the 2006 image. As a result of the increase in healthy vegetated land cover in the 2007 image, it would seem logical for the temperature to also decrease in regards to the thermal characteristics of vegetation. Thermal signature of the 2007 image show an increase in temperature values for the centre of the image which is majority urban area, and a decrease in temperatures for the surrounding countryside area. These characteristics show a greater correspondence with characteristics of the urban heat island effect where temperatures are higher in the urban area and lower in the countryside area.

\subsubsection{Selected LSTs}

The selected land cover temperatures are a clearer representation of the overall thermal signature comparison. It shows the same characteristics but at a more specific level. The same vegetated areas have higher values in the 1984 image as there are less pixels which are actually healthy vegetation within that area. Also, vegetation in the 1984 selected area could be less healthy (less moisture) which affects its emissivity and the denseness of the vegetation. A dense forest would have lower temperatures than a grassland area that is not as dense. Since parts of the selected area may have also gone through significant land cover change which would affect the change in thermal values. Selected urban areas show a inverted scenario where the 2007 image has higher values due to increase in land cover. In the 1984, much of the selected area could be barren land, therefore it would have a slightly lower thermal value than urban land covers.

\subsubsection{Urban Heat Island Effect}

From overall thermal and selected LST analysis, it shows that the urban heat island effect has increased due to the greater difference in urban and countryside temperatures, but this may not necessarily be a negative scenario. The good thing is that even though the UHI effect is more definite, overall thermal temperatures are on a decrease due to VETAC's programs and initiatives. Their land reclamation actions have increased the Greater Sudbury region in terms of visual appeal and physical characteristics of the environment, including decrease in temperatures, reduce in various kinds of pollution, and environment awareness.

\subsection{Land-cover Change}


The major goal of the following study was to quantify the conversion of barren land into vegetative areas, explore the urban heat island phenomenon by comparing thermal changes in relation to vegetation changes, and finally to observe the change in water quality by monitoring the biological activity and suspended materials.

\subsubsection{Land Cover Change Analysis}

The land-cover change analysis was completed using three change detection techniques which included image differencing, principal component analysis, and post classification comparison. Image differencing and principal component analysis were used to qualitatively observe the change in landscape while post classification was used to derive quantitative information.

Image differencing was one of the simplest method used in the project, however, the results were highly dependent on the suitable value of threshold chosen to define different classes. Several threshold class values were applied and finally the threshold value of seven was found appropriate. Out of those seven classes one class represented no change, three classes represented positive change while the other three classes represented negative change. The positive change represented increase in vegetation while the negative change signified loss of vegetation.

The major reason for merging classes as shown in figure above was information redundancy. Since +3 class had better separability it was used to demonstrate significant change. Significant change referred to areas that in 1984 were either barren/non-vegetative land or built up areas and due to the reclamation process were changed into vegetative lands. +2 and +1 represented similar information related to the conversion of sparse to dense vegetation. As a result these two classes were merged together to represent second class. 0 represented areas that were similar in both image and therefore, it was kept as a separate class. Finally, the last three classes representing negative values were also showing relatively similar information related to loss of vegetation from 1984 to 2007. Therefore, these three classes were merged together. Loss of vegetation not only represents areas that have changed into built up land but also land that is converted into barren and sparse vegetation fields.

Although image differencing provided good visual results it did not provide comparison matrix to show quantitative information about changed areas. Moreover, the results were highly dependent on the threshold value to define different classes. One of the major limitations observed in this method was over representation/estimation of some of the classes. For example, sparse to dense vegetation over represents the area, the class includes areas that in fact have dense vegetation in both images. A problem as such could have been by using more than four classes. However, such minimal problem was ignored for analytical reasons since the major objective was to analyze the areas that were converted from barren and built up areas to vegetative land, for which the results had much better representation.

Principal component method on the other hand was simpler than image differencing, and produced far more reliable results in comparison to image differencing. The PCA classes were more definitive and the classes seemed to have good separability. In comparison to 


\section{Macrothink}

Environmental Management and Sustainable Development

ISSN 2164-7682

2017, Vol. 6, No. 2

image differencing method, principal component classes had better seperability. Although no quantitative methods were used to measure separability it was however clear through visual inspection that PCA classes had better results. For example, sparse to dense vegetation class was over represented in image differencing; however, the same class was defined as areas of no change in PCA method. When the areas were examined in both images, it was clear that PCA was presenting accurate information than image differencing. The post classification comparison was the last change detection method used in the present study. Whereas image differencing and principal component analysis were used for visual analysis, post classification was used to derive quantitative information. The major advantage of this method was it not only provided comparison matrix (Table 4) but also represented change through classified images as shown in Figure 17, 18 and 19. The barren/built-up areas cover significant portion of the study area while reclaimed land represent marginally small area. However in Figure 20 which represents the classes in 2007, the change is evident as the built up/barren area has considerably decreased while the reclaimed land has been increased. Additionally, Table 4 quantitatively represents that change. From Table 4 it is clear that reclaimed land area has increased since 1984 along with the area of water and dense vegetation. The built-up/barren area on the other hand has significantly decreased. These changes justify our initial claim that through VETAC's reclamation program, large areas of Sudbury were converted into vegetative land.

The increase in the area of reclaimed land and dense vegetation is logical since it is a direct outcome of the reclamation program. However, the increase in the water area at first was perplex phenomenon, after research it was concluded that such increase is directly related to an increase in vegetation. Since increase in vegetation will also raise the moisture levels, therefore, increase in water area is relatively logical.

Table 4. Linear regression summary

\begin{tabular}{|l|r|r|r|}
\hline DOC & \multicolumn{1}{c}{ R-Square } & \multicolumn{1}{c|}{ Slope } & Intercept \\
\hline L5_June_1990_b1 & 0.21 & 0.000487 & 0.077484 \\
L5_June_1990_b2 & 0.55 & 0.000811 & 0.048809 \\
L5_June_1990_b3 & 0.62 & 0.000796 & 0.029318 \\
L5_June_1990_b4 & 0.02 & -0.000135 & 0.026229 \\
L5_June_1990_b5 & 0.64 & -0.000935 & 0.009273 \\
L5_June_1990_b7 & 0.03 & -0.000195 & 0.004683 \\
\hline L5_June_2004_b1 & 0.05 & 0.000323 & 0.074538 \\
L5_June_2004_b2 & 0.13 & 0.000559 & 0.046061 \\
L5_June_2004_b3 & 0.15 & 0.000553 & 0.027864 \\
L5_June_2004_b4 & 0.01 & 0.000164 & 0.026318 \\
L5_June_2004_b5 & 0.01 & 0.000102 & 0.008695 \\
L5_June_2004_b7 & 0.01 & 0.000163 & 0.005267 \\
\hline
\end{tabular}

\subsection{Lake Water Quality}

\subsubsection{Phosphorus Change}

When analyzing the change in phosphorus concentrations between the 1990 and 2004 image 
the majority of lakes surrounding Sudbury's urban core experienced a substantial increase with the exception of Kelly Lake which experienced a substantial decrease in phosphorus concentration. The reason for this increased concentration could be attributed to the fact that VETAC's land reclamation program annually spreads large volumes of fertilizer onto the barren land (up to $400 \mathrm{~kg}$ per hectare) - after the soil has been neutralized with lime - along with seed in order to encourage vegetation growth (Greater Sudbury, 2011). Some of this fertilizer would be carried by spring rains into nearby lakes and underlying aquifers: since in 2004 Sudbury's land had been fertilized for more than 30 years it is reasonable these extra years of fertilizer may be showing in the regression image.

\subsubsection{Dissolved Organic Carbon Change}

When analyzing the change in dissolved organic carbon concentrations between the 1990 and 2004 image, like phosphorus, the majority of lakes surrounding Sudbury's urban core experienced a moderate-to-substantial increase with the exception again being Kelly Lake which experienced a substantial decrease in DOC concentration. Defined by the United States Environmental Monitoring \& Assessment Program as organic material from plants and animals broken down and dissolved in water, the increasing concentration of DOC in Sudbury's lakes should indicate that aquatic vegetation is returning. Years of resource extraction and smelter emissions poisoned nearly 17,000 nearby lakes and streams by lowering their $\mathrm{pH}$ and killing most aquatic life (Caterpillar, 2008). The height-expansion of the smelter stacks in the area and the establishment of the environmental monitoring group VETAC have caused a substantial decrease in the acidity of surface waters and water quality is reported to be improving (Keller et al., 1986). The regression model image for DOC supports this literature in that the concentration of this dissolved organic matter increased from the 1990 image to the 2004 image: higher amounts of DOC indicates more productive water since organic matter must live before it can die and break down.

\subsubsection{Error Analysis Considerations}

It should be acknowledged that these results should be taken with a grain of salt and quantitative analysis using these output regression images (such as total change or average concentration) should be avoided. Since the average error in three of the four output images was considered to be substantial the confidence in their values is low. The attempt to map the spatial distribution and concentrations of these water quality parameters was still warranted, however, since the observed relationship between the in-field measurements and the satellite sensor values remained consistent between the 1990 and 2004 data. Though not precise the 1990 DOC regression image did produce a satisfactory average error of 1.72 and therefore, according to the statistics, can demand a higher confidence in the accuracy of its output pixel values. It is also apparent that the regression-model image error directly related to the original R-square value of the TM-WQP relationship: 1990-DOC had the highest R-square value of 0.62 and produced the lowest average error. In order to achieve the most accurate results spatial coordinates and precise time of field-water quality sampling should be coordinated with the overpassing sensor. Hyperspectral analysis may also increase the accuracy of the results given its ability to isolate the electromagnetic spectrum into narrower bands. 


\section{Conclusion}

Through analysis, this study revealed informative results which were both interesting and predicted. The three areas within the study: land-cover change; thermal analysis; and water quality analysis, provided a positive confirmation of VETAC's environmental restoration and improvement initiatives. Significant changes have occurred within the last 23 years in the Sudbury area, allowing this study to generate quantitative data about Sudbury's environmental conditions in the past and present.

Thermal analysis revealed results in relation to the land-cover analysis. Outcomes show a decrease in temperatures in the 2007 image due to the increase in dense vegetation and decrease in built-up and barren land-covers. On the other hand, 2007 image displays a closer relationship to the urban heat island phenomenon, as high temperatures are present in the Sudbury city core and lower temperatures at countryside areas. Comparisons also show the effect of having healthy dense vegetation in regards to controlling land surface temperatures.

In the water quality analysis, outcomes were generated from acquiring historical in-situ water quality data that corresponded with Landsat image capture dates, extracting reflectance values from Landsat image, and by using linear regression models to study relationships between extracted reflectance and historical in-situ data. Results indicated increase in phosphorus and DOC levels in lakes around Sudbury except for Lake Kelly. Increase in phosphorus levels maybe due fertilizing efforts conducted by VETAC to improve vegetation growth. And DOC levels could be a result of increase organic matter due to improved water quality. Error analysis shows that DOC distribution maps are slightly more precise than phosphorus distribution maps.

Results of this study would be useful in similar regions for organizing environmental programs and other initiatives. This information provides authorities with data about Sudbury's current environmental conditions and ideas of other improvements that maybe required. Generated outcomes could also be helpful to other regions that wish to improve their environment.

\section{References}

Coll, C., Galve, J. M., Sanchez, J. M., \& Caselles, V. (2010). Validation of landsat-7/ETM+ thermal-band calibration and atmospheric correction with ground-based measurements. IEEE Transactions on Geoscience and Remote Sensing, 48(1), 547-555.

https://doi.org/10.1109/TGRS.2009.2024934

Keller, W., et al. (1986). Water Quality Improvements in the Sudbury, Ontario, Canada Area Related to Reduced Smelter Emissions. Water, Air, and Soil Pollution, 31. https://doi.org/10.1007/978-94-009-3385-9_176

Kennedy, R. E., Townsend, P. A., Gross, J. E., \& Cohen, W. B. (2009). Remote sensing change detection tools for natural resource managers:Understanding concepts and tradeoffs in the design of landscape monitoring projects. Remote Sensing of Environment, 1382-1396. https://doi.org/10.1016/j.rse.2008.07.018 


\section{Macrothink}

Petropoulos, G., Carlson, T., Wooster, M., \& Islam, S. (2009). A review of Ts/VI remote sensing based methods for the retrieval of land surface energy fluxes and soil surface moisture. Progress in Physical Geography, 33(2), 224-250.

https://doi.org/10.1177/0309133309338997

Southworth, J. (2004). An assessment of landsat TM band 6 thermal data for analysing land cover in tropical dry forest regions.

Srivastava, P. K., Majumdar, T. J., \& Bhattacharya, A. K. (2009). Surface temperature estimation in singhbhum shear zone of india using landsat-7 ETM+ thermal infrared data. Advances in Space Research, 43(10), 1563-1574. https://doi.org/10.1016/j.asr.2009.01.023

Zhang, Y., Odeh, I. O., \& Han, C. (2009). Bi-temporal characterization of land surface temperature in relation to impervious surface area, NDVI and NDBI, using a sub-pixel image analysis. ITC Journal, 11(4), 256-264. https://doi.org/10.1016/j.jag.2009.03.001

Zhang, Z., \& He, G. (2008). Radiometric calibration of landsat 5 TM data. Keji Daobao / Science \& Technology Review, 26(7), 54-58.

\section{Copyright Disclaimer}

Copyright for this article is retained by the author(s), with first publication rights granted to the journal.

This is an open-access article distributed under the terms and conditions of the Creative Commons Attribution license (http://creativecommons.org/licenses/by/3.0/). 